\title{
ENTRE LAS DEVOCIONES POPULARES Y EL CULTO A LOS MUERTOS EN EL PAISAJE RITUAL
}

\author{
María Azucena Colatarci \\ Ricardo Vidal
}

Resumen: Este trabajo tiene por objetivo aportar reflexiones acerca de las vinculaciones y desvinculaciones entre las devociones populares (entendiendo por tales las conocidas técnicamente en algunos ámbitos académicos como canonizaciones populares) y el culto a los muertos en contextos sociales de tradición católica ya que, como hemos expuesto con anterioridad, entendemos que dichas devociones tienen su origen en el culto a los muertos del cual se escinden para erigirse en devociones con dinámica propia. Asimismo y en estrecha vinculación con lo antes dicho se plantea que en el denominado paisaje ritual se plasman los signos de la religiosidad popular.

Palabras clave: Devociones populares — culto a los muertospaisaje ritual—religiosidad popular.

Enviado a dictamen: 28 de enero de 2008.

Aprobación: 28 de agosto de 2008.

Dra. María Azucena Colatarci, magister en Cultura y Sociedad, mención Sistema de Creencias, Instituto Universitario Nacional del Arte, Buenos Aires, Argentina, temas de especialización: religiosidad tradicional y popular, sistema de creencias, folklore; correo electrónico: mazucenac@hotmail.com. Dr. Ricardo Vidal, experto en Medios de Comunicación Masivos, Instituto Universitario Nacional del Arte, Buenos Aires, Argentina, temas de especialización: religiosidad tradicional y popular, sistema de creencias; correo electrónico: rigeminis@fibertel.com.ar
Abstract: This researchintends to contribute reflections of the links and severances between the popular devotions (understanding by such the technically known ones by some academic scopes as popular canonizations) and the cult to the dead in social contexts of catholic tradition. As we have exposed previously, we understand that these devotions have their origin in the cult to the dead from which they separate to rise in devotions with their own dynamics. Also and in close liaison with what was previously said one considers that in the denominational ritual landscape, the signs of the cult to the dead and the popular devotions are shaped.

Key words: Popular devotions, cult to the dead, ritual landscape, popular devotions.

\section{Introducción}

E n este trabajo nos proponemos reflexionar acerca de las vinculaciones y desvinculaciones entre las devociones populares y el culto a los muertos, así como ofrecer un aporte sobre la estrecha relación que la exteriorización de dichas manifestaciones tiene con el paisaje ritual.

El material documental que da soporte a estas reflexiones ha sido colectado en el noroeste de la República Argentina, más precisamente en la zona de valles, quebradas y punas de la provincia de Jujuy en el 
transcurso de sucesivas campañas realizadas entre los años 2006 y 2007, y se complementa con documentación prospectiva (también de primera mano) obtenida en La Habana (Cuba) en el 2007.

La zona en la que se realizaron los trabajos en la República Argentina está habitada por población que es portadora de una cultura de síntesis (Geertz, 1987) ya que se ha conformado a partir de los sucesivos asentamientos humanos portadores de diversas tradiciones culturales que se reconfiguraron con el tiempo hasta generar un complejo sistema de representaciones.

La problemática objeto de este trabajo se inscribe, en principio, en el campo de la religiosidad tradicional/ popular en contextos sociales de tradición católica; en este sentido consideramos aspectos tanto de lo que denominamos la esfera oficial de la Religión Católica como de la no oficial o popular, ya que ambas esferas se complementan y hasta, en algunos casos, se retroalimentan. En lo que respecta al campo de la esfera oficial se destaca que la Iglesia reserva un lugar de preferencia vinculado a las ánimas de los muertos, como a la de los santos en tanto intermediarios - estos últimosentre los hombres y Dios. También corresponde a esta esfera el denominado culto a los muertos ya que tiene asignado un día en particular en el año litúrgico (2 de noviembre), como también se recuerda a los santos difuntos en forma expresa en el desarrollo ritual de la misa. En cuanto a la esfera popular, se inscriben en ésta un conjunto de actos rituales que tienen su soporte en las normas institucionales del catolicismo, pero que exceden el control de la Iglesia y siguen su propia lógica y desarrollo en torno a la cuestión del culto a los muertos $\mathrm{y}$ al de las devociones populares.

\section{Algunas consideraciones conceptuales}

Como ya hemos planteado, este trabajo trata acerca de cuestiones inscritas en lo que entendemos como religiosidad tradicional/popular en un contexto social de tradición católica, en el que aún están vigentes algunas creencias del sistema de representaciones de la tradición andina prehispánica. ${ }^{1}$

En principio empleamos el término religiosidad para referirnos a las manifestaciones vigentes y espontáneas que se practican sin supervisión institucional pero que permiten advertir, en la praxis, que tienden a religar al hombre con la esfera de lo sagrado, mediante prácticas vinculadas con las devociones a diversas figuras del catolicismo, o a personajes santificados popularmente como las ánimas o la Pachamama (Madre Tierra) entre otras posibilidades. Lo cierto es que todas estas manifestaciones vigentes de la religiosidad son practicadas por la gente de modo espontáneo y se transmiten en forma empírica, asistemática, sin intervención de ministros específicos, y se reproducen en sus propios contextos sociales; no obstante se destaca que en el noroeste argentino se presenta una doble situación ya que por una parte las instituciones tienen estrategias de apropiación de las expresiones tradicionales/populares ${ }^{2}$ y, por otra, el pueblo asimila las formas institucionales refigurándolas y resignificándolas. ${ }^{3}$

Con respecto a la adjetivación que empleamos para estas múltiples manifestaciones vigentes de la religiosidad, es decir tradicional/popular, utilizamos estos adjetivos como sinónimos ya que desde nuestra posición la categoría tradicional es central, no en el sentido de antigualla sino del arraigo en el pasado que una manifestación cultural tiene al interior de un grupo sociocultural; esto significa que consideramos a lo popular también tradicional. Por lo expuesto no nos detendremos en las manifestaciones que consideramos pasajeras a partir de los datos de campo, ya que dichas expresiones (las pasajeras) no sólo carecen de arraigo en el pasado sino que, además, por esa misma circunstancia no inciden en la construcción y en el sentido de identidad del grupo, o a lo que éste considera propio.

En síntesis, y por lo antes dicho, con la expresión religiosidad tradicional/popular nos referimos al con- 
junto de manifestaciones, tanto urbanas como rurales, que resultan de las prácticas vinculadas con lo religioso en tanto expresiones espontáneas que no están sujetas, ni normadas, por institución alguna; aunque a partir de su estudio se puedan advertir vinculaciones ideológicas, estéticas y formales con algunas prácticas normadas por las Iglesia Católica.

Como ya hemos dicho, consideramos que las diversas manifestaciones de la religiosidad tradicional/ popular son aquellas que tienen por objeto religar las esferas de lo sagrado y de lo profano pero, además, se inscriben en las prácticas del marco no oficial institucional (aunque estén vinculadas con el mismo) y entendemos que es este último marco el que posibilita la coexistencia de diversas tradiciones religiosas en el contexto de la religiosidad tradicional/popular, ya que los distintos rituales se concretan paralela o complementariamente, sin conflicto entre las mismas y/o entre las diferentes personas practicantes. ${ }^{4}$

Además queremos destacar que las múltiples manifestaciones de la religiosidad tradicional/popular, al estar vigentes, tienen la particularidad de ser flexibles y plásticas, motivo por el que sufren modificaciones en la praxis, además de resignificarse, y de este modo se producen y reproducen tanto en sus propios contextos, como en los nuevos, cuando es el caso.

En este sentido, y teniendo en cuenta que una importante cantidad de rituales y signos por medio de los que se expresa la religiosidad tradicional/popular se producen en espacios públicos, es que vinculamos el tema en cuestión con el concepto de paisaje ritual, es decir con el espacio en el que se producen y reproducen las manifestaciones religiosas tradicionales/populares, en particular las que son objeto de nuestro presente estudio. Asimismo nos interesa destacar que la utilización del concepto de paisaje ritual también se vincula con la importancia que asignamos a la problemática del espacio y su vinculación con el sistema de creencias. Como es sabido el espacio es heterogéneo y en tanto tal sus discontinuidades dan cuenta del sistema de representaciones de sus habitantes. Es así que en la zona de nuestro trabajo se puede distinguir en el paisaje ritual, además de las iglesias, pequeñas capillas, oratorios y cementerios, otros espacios sagrados como por ejemplo las apachetas, ${ }^{5}$ los santuarios, ${ }^{6}$ cruces y ermitas ubicados tanto a la vera de los caminos como en otros variados lugares que hacen referencia a diversos aspectos del sistema de creencias de la gente; no obstante, en algunos casos el paisaje ritual no da cuenta de los lugares sagrados ya que los mismos se advierten sólo en los momentos en que se realizan los rituales correspondientes. ${ }^{7}$

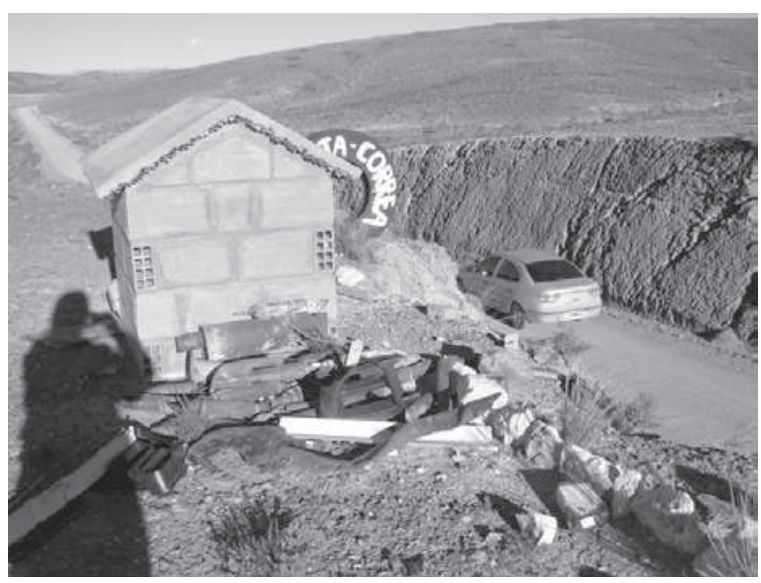

2007- Provincia de Jujuy (camino entre Santa Catalina y La Quiaca en la Puna jujeña). Lugar dedicado a la Difunta Correa. Forma parte del paisaje ritual (foto: archivo personal).

Respecto al culto a los muertos (o devoción a las ánimas) compartimos y partimos del planteo de Krause Yornet referido a la provincia de San Juan y que, entendemos, es posible generalizar:

...Este culto [...'la devoción a las ánimas'...] se expresa en dos ámbitos diferenciados: el familiar y el social. El primero es la veneración a los muertos familiares 
en los altares domésticos; el segundo, se realiza en Santuarios de difuntos mitificados por la creencia popular (Krause Yornet, 1987:65).

Nos interesa aclarar que no abordaremos la cuestión referida al primer aspecto sino que nos centraremos en lo que la autora denomina el culto social, es decir, el que se genera y practica en torno a los espacios destinados a las ánimas - culto a los muertos - y al de los denominados santos populares que son objeto de la devoción popular.

La instancia del culto social en el contexto de la religiosidad tradicional/popular presenta una fuerte impronta vinculada con el culto a las ánimas y a las devociones populares (que son los llamados santos populares) respecto de lo cual consideramos que la devoción a estos personajes - los santos populares - se escinde del culto a los muertos (o devoción a las ánimas) al adquirir una dinámica propia.

También creemos, en esta línea de pensamiento, que las cruces, nichos y ermitas ubicados en espacios públicos a la vera de los caminos - que modifican el espacio, generando un paisaje ritual que da cuenta de acontecimientos trágicos acaecidos a personas anónimas que así permanecerán después de muertos- se instalan como una instancia de articulación ritual y liminal entre la esfera del culto privado o familiar y el culto social, por lo que es posible encontrar señales de ciertos rituales vinculados al culto a las ánimas como velas encendidas, entre otras manifestaciones. Entonces y parafraseando a Oreste Plath:

Nace una "Animita" por misericordia del pueblo en el sitio en el que aconteció una "mala muerte". (...), los restos descansan en el cementerio, por lo que se honra el alma, la "ánima” (Oreste Plath, 1995: 9).

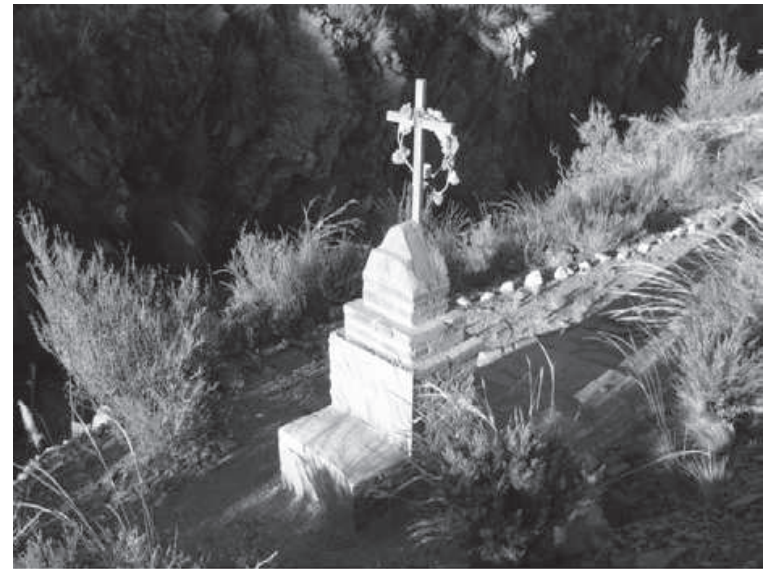

2007 - Jujuy (Cuesta de Toquero, camino de Santa Catalina a La Quiaca, puna jujeña). Ermita a la vera del camino que señala el lugar de una muerte repentina, se ve desde el camino (foto: archivo personal).

Por lo expuesto entendemos que dichos espacios, además de ser lugares de culto social a los muertos, son articuladores y liminares ya que, en algún momento, uno de estos personajes deja su anonimato y trasciende a partir de cierto acontecimiento portentoso que genera el culto social fundado en la devoción popular a esta alma que dejó su anonimato. Es a partir de este momento en que consideramos que este tipo de devociones adquiere una dinámica propia, distinta del culto a los muertos o a las ánimas. Es evidente que tanto el culto a los muertos en los espacios públicos a la vera de los caminos (o en sus cercanías), así como el culto a las devociones populares se inscriben en el ámbito de la religiosidad tradicional/popular, es decir en el campo de lo no oficial, y sus signos son reconocibles en el paisaje ritual. 


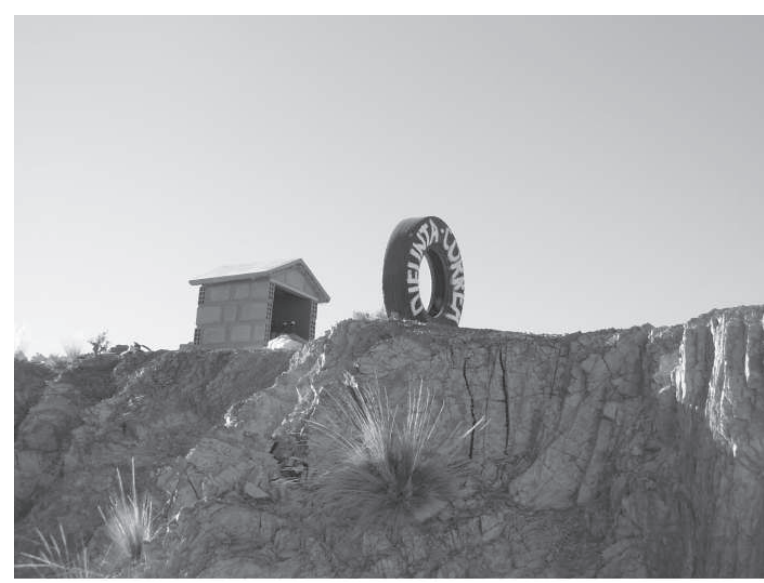

2007. Provincia de Jujuy (camino entre Santa Catalina y La Quiaca en la Puna jujeña). Instauración específica a la Difunta Correa. Toma realizada desde el camino (foto: archivo personal).

Esta cuestión del culto a los muertos también se verifica en los cementerios, espacio que merece un estudio particular por la multiplicidad de comportamientos y rituales que se producen, a pesar de ser un lugar en el que las personas se deben atener a ciertas normas institucionales. Sin embargo lo que nos interesa destacar es que el cementerio también se puede apreciar en términos de paisaje ritual ya que se advierten, en principio y de modo muy general, actitudes que son la mera visita al lugar donde está enterrado un ser querido (con la consiguiente ofrenda), como también el encendido de velas (en algunos casos) que connota un comportamiento ritual devocional; en ambos casos consideramos que se trata del culto familiar. En tanto que también en algunos cementerios se erigen espacios que darán por resultado el culto social en torno a alguna devoción popular surgida y escindida del contexto del culto a los muertos, como por ejemplo el de la Almita Sibila en el cementerio de la ciudad de San Salvador de Jujuy entre otros ejemplos (Foto 4). En estos últimos casos se hace notar que la persona que ha fallecido se encuentra en ese lugar mientras que, en los casos de las instauraciones a la vera de los caminos, se trata de lugares que señalan acontecimientos pero que no son entierros.

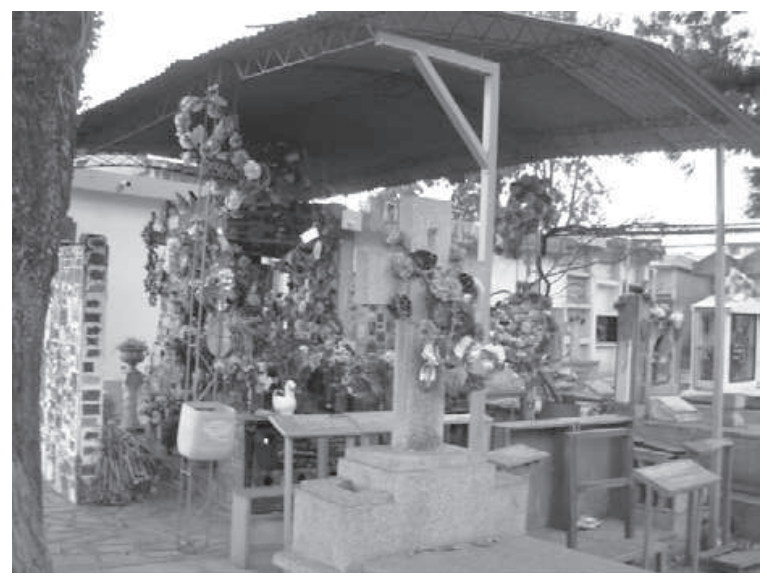

2007. Jujuy (R. A.). Cementerio de la ciudad de San Salvador de Jujuy. Tumba santuario a la Almita Sibila (foto: archivo personal).

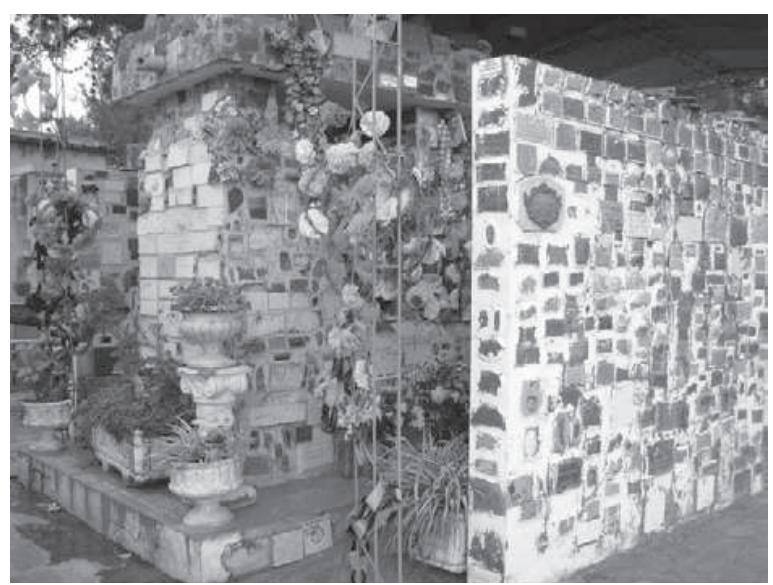

2007. Jujuy (R. A.). Cementerio de la ciudad de San Salvador de Jujuy. Tumba santuario a la Almita Sibila, vista parcial de las placas de agradecimiento (foto: archivo personal).

Diversos autores han estudiado la temática de las denominadas "canonizaciones populares", "animitas", "almas milagrosas" y otros modos de llamar a variados 
personajes, depositarios de la devoción popular en tanto son concebidos con capacidades para producir milagros, es decir, de operar en forma portentosa logrando que las necesidades de quienes en ellos creen se concreten a través de su intercesión. Resulta evidente que la concepción acerca de estos personajes se asemeja fuertemente a la que los creyentes tienen respecto de los santos reconocidos por la Iglesia Católica, es decir, los santos oficiales. En este sentido encontramos aquí una disyunción conceptual entre lo oficial y lo no oficial que, no obstante, se conjuga en lo que denominamos devoción popular, es decir, los modos espontáneos, populares, que emplean las personas para vincularse con el objeto de sus creencias ya se trate de santos oficiales o no.

\section{Desarrollo}

El material documental que describiremos, a partir del cual se presenta este trabajo, ha sido recolectado en la provincia de Jujuy y considera dos tipos de espacios en términos de paisaje ritual: por una parte las diversas instauraciones que se encuentran a la vera de los caminos (particularmente la ruta nacional № 9 y algunas provinciales) y sus adyacencias, y por otra el cementerio de la ciudad de San Salvador de Jujuy en una breve comparación con la Necrópolis de Colón en La Habana, Cuba. De modo que tal como hemos expresado antes, se trata de manifestaciones de culto social vinculadas con, y escindidas de, la devoción a los muertos inscritas en el campo de la religiosidad tradicional/popular.

En ese sentido distinguimos:

a. a) A la vera de los caminos:

b. a.l) las ermitas, nichos y diversos espacios que señalan el lugar en el que anónimos seres fueron sorprendidos por la muerte y que la piedad popular utiliza no sólo para recordarlos, sino para ofrendarles velas y flores en diferentes momentos;

c. a.2) los espacios sagrados que adquieren casi el carácter de santuarios que se erigen y reproducen para veneración de los santos populares - canonizaciones populares - entre los que es necesario establecer la siguiente diferenciación:

d. a.2.1) el espacio original, o santuario principal, que es aquel en el que se originó el culto a la devoción de que se trate, $y$

e. a.2.2) la reproducción de estos en diferentes lugares, situación que se produce por la devoción de la gente que difunde su creencia y deja señales de ella. Ejemplos de a.2 y sus subdivisiones son Pedrito Sangüeso (Salta), la Difunta Correa (San Juan) y el Gauchito Gil (Corrientes) entre otras muchas devociones populares o canonizaciones populares. El caso de estas dos últimas devociones (Difunta Correa y Gauchito Gil) adquiere relevancia ya que a lo largo de las rutas, así como en otros sitios, es posible encontrar profusión de santuarios en su honor (a una o al otro) ya que la devoción de sus creyentes los ha hecho trascender las fronteras de sus lugares de origen.

f. b) En los cementerios: En ellos se suma a la piedad común de quienes visitan a sus muertos la presencia, en algunos casos, de tumbas que se han convertido en santuarios ya que la gente dice, así como las placas y los ex votos que tienen entre otros signos, que quien allí yace es un alma milagrosa a quien conocen con nombre, apellido e historia (aunque esta última se ajuste o no a la historia), así como la enumeración de diversos hechos portentosos. En este último caso se inscriben devociones como las del Mono Arana en el cementerio de la ciudad de Orán (Salta), de la Almita Sibila (o Sivila) en el cementerio de la ciudad de San Salvador de Jujuy (Jujuy), en la República Argentina, así como en la Necrópolis de Colón en la ciudad de la Habana en Cuba, donde se encuentra la tumba santuario de la llamada Milagrosa y que hemos seleccionado como un punto inicial de comparación. 
Con el objeto de ordenar la presentación consideraremos los siguientes aspectos:

\section{Los personajes}

En el caso de las cruces y ermitas (entre otras pequeñas construcciones) que se encuentra a la vera de los caminos y que señalan sitios en los que muertes trágicas o sorpresivas tuvieron lugar, se trata de personas anónimas para quienes no las conocieron y en el sentido de que no trascienden ese espacio. El lugar queda señalado y la gente (en general sus conocidos) les llevan flores y les encienden velas a pesar de que allí ya no están sus cuerpos. Si bien los actos rituales antes mencionados se reproducen en el tiempo, en muchos casos hay signos visibles que permiten advertir que el lugar ha dejado de ser visitado, y a pesar de que consideramos que son variadas las causas de tal situación, no serán estudiadas en esta ocasión.

Los casos de Almita Sibila, Gauchito Gil (ambos en la República Argentina) y de la Milagrosa (Cuba) forman parte de las denominadas canonizaciones populares, $\mathrm{o}$ santos populares, categoría que involucra a un conjunto de individuos a los que la gente les atribuye capacidades para obrar milagros. Entre otras razones expuestas por distintos autores consideramos que lo que caracteriza a estos santos es el carecer del reconocimiento de la Iglesia Católica, a pesar de que sus creyentes los conciben del mismo modo que a los santos oficiales (cuestión ya planteada en la introducción), sin embargo, a pesar de esta similitud es el espacio de culto el que también los diferencia ya que sus altares suelen estar en espacios públicos, a la vera de los caminos $u$ otros lugares similares, como también en los cementerios, es decir, nunca dentro de las Iglesias, de modo que la localización da cuenta de su carencia de reconocimiento oficial claramente observada por los devotos.

En nuestro ejemplo se distinguen dos mujeres, Almita Sibila y la Milagrosa que se diferencian no sólo porque una era argentina y la otra cubana, sino porque de acuerdo a lo que de ellas se sabe tuvieron historias personales muy distintas, sólo las une un triste y prematuro final (principios del siglo XX) y su posterior capacidad milagrosa.

Cuadro comparativo de las devociones populares a Almita Sibila (Argentina) y La Milagrosa (Cuba).

\begin{tabular}{|c|c|c|}
\hline & Almita Sibila & La Milagrosa \\
\hline País & Argentina & Cuba \\
\hline Cuidad & $\begin{array}{l}\text { San Salvador de Jujuy (Capital de la provincia } \\
\text { de Jujuy). }\end{array}$ & La Habana (Capital de Cuba). \\
\hline $\begin{array}{l}\text { Lugar de emplazamiento de la tumba santu- } \\
\text { ario }\end{array}$ & $\begin{array}{l}\text { Cementerio municipal de la ciudad de San } \\
\text { Salvador de Jujuy. }\end{array}$ & Necrópolis de Colón en la ciudad de La Habana. \\
\hline $\begin{array}{l}\text { Materiales y ornamentación de la tumba } \\
\text { santuario }\end{array}$ & $\begin{array}{l}\text { Tumba santuario humilde, con placas, incrusta- } \\
\text { ciones de ex votos en paredes precarias, inscrip- } \\
\text { ciones realizadas con pintura, tiza e incisas, vel- } \\
\text { eros, floreros entre otros objetos, todo ubicado } \\
\text { formando un conjunto heterogéneo y ubicado } \\
\text { según la espontaneidad de los devotos. }\end{array}$ & $\begin{array}{l}\text { Tumba santuario con lápida y escultura construi- } \\
\text { das en mármol de carrara. } \\
\text { Las placas de agradecimiento se encuentran } \\
\text { ubicadas en un orden preciso y no se advierte } \\
\text { la presencia de velas ni otro tipo de objetos, con } \\
\text { excepción de las flores. }\end{array}$ \\
\hline Fecha de muerte & Principios del siglo XX. & Principios del siglo XX \\
\hline Sexo & Femenino. & Femenino \\
\hline Situación socio-cultural & Humilde, vivía en las afueras de la ciudad. & $\begin{array}{l}\text { Clase social adinerada, casada, vivía en la } \\
\text { ciudad }\end{array}$ \\
\hline Causa de la muerte & Violación seguida de asesinato. & $\begin{array}{l}\text { Al momento de nacer su primer hijo que } \\
\text { también murió y están enterrados en la misma } \\
\text { tumba }\end{array}$ \\
\hline
\end{tabular}


En el cuadro anterior se clarifica la comparación entre ambas devociones populares, se presenta el siguiente cuadro:

El cuadro permite advertir las similitudes y diferencias entre estas dos devociones populares surgidas en lugares tan distantes pero que (y a pesar de los procesos históricos diferentes) parecen compartir cierta tradición del culto a los muertos que da lugar a la emergencia de devociones populares en los términos que aquí estamos analizando.

Entre las similitudes se destacan el sexo, la muerte prematura e imprevista, el encontrarse ubicadas sus tumbas santuarios en los cementerios de ciudades, que ambas murieron a principios del siglo XX y, esencialmente, que la gente les solicita su intercesión la que, evidentemente se concreta ya que un análisis de las placas - y otros recordatorios - que se encuentran en ambos lugares son descriptivos de los portentos realizados según la perspectiva de sus devotos.

Con respecto a las diferencias que se advierten entre ambas figuras consideramos que no son relevantes con respecto a su calidad de devociones populares.

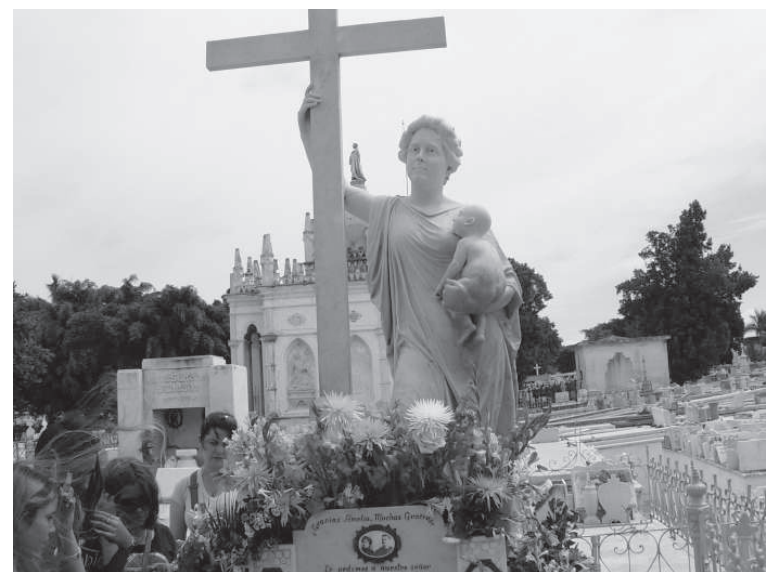

2007. Necrópolis de Colón. Tumba santuario a La Milagrosa. Devotos visitándola. A la derecha se ve parte de los espacios destinados a las placas de agradecimiento. La Habana. Cuba (foto: archivo personal).

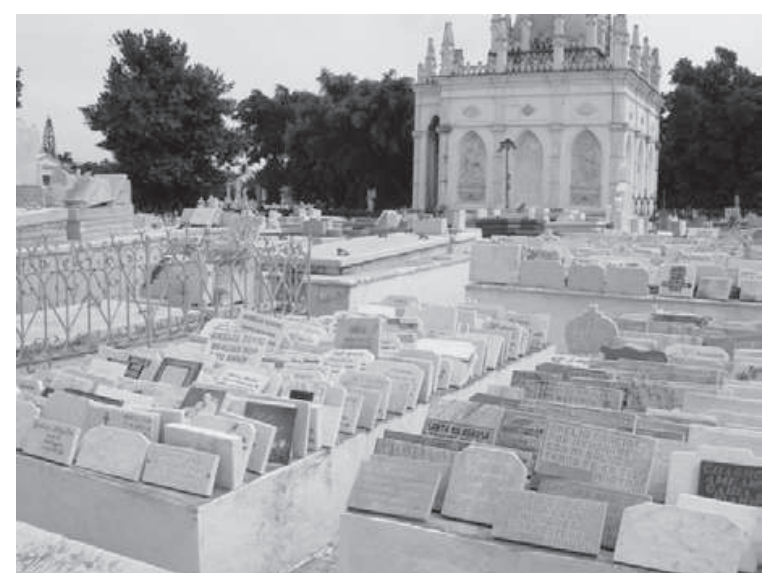

2007. Necrópolis de Colón. Placas de agradecimiento a La Milagrosa en espacios contiguos a la tumba santuario. La Habana. Cuba (archivo personal).

Por otra parte hemos seleccionado una figura masculina, la del llamado Gauchito Gil, gaucho de la campaña correntina cuya historia se sitúa en la segunda mitad del siglo XIX, por la profusión que ha adquirido en los últimos años.

Las dos devociones populares (canonizaciones populares) femeninas, Almita Sibila y la Milagrosa reciben el culto de sus devotos, en realidad pedidos y agradecimientos en el cementerio en que se encuentran sus tumbas, en tanto que la figura masculina seleccionada tiene la peculiaridad de ser una de las devociones que, además de recibir honras en su santuario principal (Mercedes, en la provincia de Corrientes) cuenta con multiplicidad de lugares de culto instaurados por sus devotos que, de ese modo, reproducen y difunden su devoción. ${ }^{8}$

A continuación nos referiremos en particular a esta última figura masculina.

$\mathrm{Al}$ interior de la heterogénea multitud de santos populares se recorta la de los denominados gauchos milagrosos tales como Bairoletto, Altamirano y Cubillos entre otros, además del Gauchito Gil, cuyas historias se desarrollaron en la República Argentina. En este sentido 
se advierte que los gauchos milagrosos, además de lo ya apuntado, tienen en común su situación de gauchos, el tener problemas con la justicia o el orden institucional por diversas circunstancias, asumir un comportamiento robinsoniano (Chumbita, 1999 entre otros) y, por esa causa, gozar de la complacencia de sus coetáneos hasta que, en un momento dado su vida es tronchada por algún representante del poder en alguna situación que es considerada injusta por el pueblo, de allí a la génesis de su santidad popular poco hay.

En este contexto se presenta la figura del Gauchito Gil, oriundo de la provincia de Corrientes en la República Argentina, quien tuvo actuación hacia la segunda mitad del siglo XIX. Diversas versiones circulan acerca de su vida y muerte similares a las de otros gauchos milagrosos de la misma época. También hay una profusa narrativa oral que da cuenta de sus portentos, aún desde la que narra el primer milagro operado por él en la persona del hijo de uno de sus verdugos. Por otra parte hay que tener en cuenta que no sólo por los estudios sistemáticos que se han realizado en los últimos años sobre éste y otros personajes similares, sino fundamentalmente por la importante difusión de su culto y devoción, las narraciones acerca del Gauchito Gil (vida, obra, muerte y milagros) han circulado de la oralidad a la escritura y de ésta a la oralidad nuevamente en una dinámica de actualización sostenida.

Por lo anterior, y en virtud de la profusión de espacios de culto que se van instaurando a medida que se difunde su devoción, se ha generado una importante y variada parafernalia que está inserta en el mercado comercial entre las que se distinguen: velas rojas, estampas, novenas, íconos con su imagen, jabones, lociones, banderines y cintas rojas entre otras variadas e ingeniosas propuestas de consumo ritual.

¿Qué sabe la gente del Gauchito, qué dice? Que era un gaucho bueno, que no quiso derramar la sangre de sus hermanos, que robaba a los ricos para dar a los pobres, que todo lo que se le pide se cumple, que era correntino, que lo mataron y lo colgaron de los pies, que tenía un San
La Muerte incrustado debajo de la piel porque era muy devoto del mismo y, en fin, un sinnúmero de milagros acaecidos. Para cualquier devoto del Gauchito lo más importante es poder, en algún momento, ir a visitar su santuario principal en Mercedes, en la provincia de Corrientes.

Sin embargo se le venera a lo largo y ancho del país en infinidad de santuarios específicos. Entendemos que tal situación se funda (entre otras causas) en que en muchos casos el primer modo de cumplir con el Gauchito es instaurar su imagen en un lugar específico y cuidarlo.

En diversos trabajos de campo vimos, a lo largo de los caminos, multiplicidad de espacios de culto dedicados al Gauchito Gil.

Si se tiene en cuenta que en los últimos años ha proliferado a la vera de los caminos gran cantidad de espacios de culto dedicados al Gauchito (denominación cariñosa empleada por sus devotos y generalizada para referirse al mismo), es posible advertir que el paisaje ritual permite distinguir sus santuarios y diferenciarlos tanto de los de la Difunta Correa por ejemplo, como de las ermitas que se erigen para recordar a los muertos en accidentes. En ese paisaje ritual se distinguen los espacios de culto dedicados al Gauchito particularmente porque:

a. La instauración está cerca o debajo de un árbol;

b. En el lugar se encuentra instalada una imagen de bulto que representa al Gauchito Gil;

c. Elícono se encuentra en una cavidad (puede ser de un árbol, en una pequeña construcción o en una urna entre otras posibilidades);

d. El lugar está señalado por la profusión de banderines y/o estandartes de color rojo, en realidad es el color predominante ya que, según dicen, esto estaría vinculado con la posible filiación política del personaje;

e. Es corriente que haya un cartel, u otro tipo de señalización que especifique el nombre del espacio: GAUCHITO GIL.

136 Revista LiminaR. Estudios sociales y humanísticos, año 6, vol. VI, núm. 2, diciembre de 2008, Tuxtla Gutiérrez, Chiapas. ISSN: 1665-8027 
Del material con el que contamos seleccionamos para esta ocasión el correspondiente al mes de enero de 2006 en que observamos dos espacios de culto, casi contiguos pero diferenciados, dedicados al denominado Gauchito Gil en la provincia de Jujuy (República Argentina) ubicados a la vera de la ruta nacional № 9 sobre la margen derecha con rumbo norte-sur, a pocos kilómetros de la capital de la provincia homónima a la altura de la zona denominada Alto Comedero.

Cuando se presta mayor atención, y lejos de mirar ese paisaje ritual como tal se procede a observarlo con mayor detenimiento, se advierte que junto al Gauchito Gil es común hallar a San La Muerte. ${ }^{9}$ Dice la tradición popular que él mismo era devoto de San La Muerte.

La selección de los lugares fue, de algún modo, arbitraria. Sin embargo tuvimos en cuenta: a) que en el mismo paraje, y sobre la misma margen, hay dos santuarios; b) la magnitud del que se encuentra más al sur que, además, está flanqueado por dos espacios dedicados a sendos San La Muerte; c) que entre ambos santuarios al
Gauchito hay un suerte de marcas imperceptibles, a ras del pasto, de pequeños banderines rojos; d) su cercanía con la ciudad Capital de la provincia. Por otra parte la documentación central corresponde al día 8 de enero que, según dicen, corresponde a la fecha en que lo mataron y por lo tanto en su santuario principal (Mercedes), como en cada uno de los que han sido instaurados en distintos puntos del país, se pone en acto la devoción popular al Gauchito Gil.

Para diferenciar los espacios de culto relevados denominaremos Santuario Norte al que está más cerca de la ciudad y Santuario Sur al que está en esa dirección sobrepasando al primero. A continuación ofrecemos un cuadro comparativo entre ambos espacios de culto. Con respecto al que denominamos Santuario Norte los que detentan el control del mismo son el padre y el hijo, jefes de ambas familias nucleares vinculadas al lugar, los mismos se dedican a trabajos varios en los caminos y manifiestan su agradecimiento al Gauchito al que invocan en momentos críticos en los cuales Él los asiste. De

\begin{tabular}{|c|c|}
\hline Santuario Norte & Santuario Sur \\
\hline $\begin{array}{l}\text { - Margen derecha de la ruta en dirección norte sur. } \\
\text { - El lugar está señalizado con un cartel. } \\
\text { - Hay un árbol. } \\
\text { - Predominio del color rojo. } \\
\text { - Es de escasa envergadura e involucra a dos familias nucleares con } \\
\text { vinculación patrilineal que son los dueños. } \\
\text { - En el lugar se encuentra una instalación anterior, con su correspon- } \\
\text { - El Giente ícono que, según dicen, no saben de quién es. } \\
\text { - El clo clima encuentra reinante el interior de una especie de casita, allí los circunstantes es distendido entre } \\
\text { - El sagrado y profano. } \\
\text { - El lugar es cuidado y mantenido por sus dueños. }\end{array}$ & $\begin{array}{l}\text { - Margen derecha de la ruta en dirección norte sur. } \\
\text { - El lugar está señalizado con un cartel. } \\
\text { - Hay un árbol. } \\
\text { - Predominio del color rojo. } \\
\text { - Es de gran envergadura, una mujer aduce ser la dueña y controla } \\
\text { las actividades. } \\
\text { - Aambos lados de la construcción en la que habitualmente se encuen- } \\
\text { tra la imagen del Gauchito, se erigen dos construcciones dedicadas } \\
\text { a San La Muerte que contienen profusión de íconos del mismo en } \\
\text { los más variados tamaños, posiciones y ropajes. } \\
\text { - El Gauchito Gil es una figura tallada en tamaño natural que ostenta, } \\
\text { además, cabellera. } \\
\text { - El clima reinante entre los circunstantes es distendido entre sagrado } \\
\text { y profano. } \\
\text { - El lugar es cuidado y mantenido por su dueña y ayudantes. }\end{array}$ \\
\hline
\end{tabular}

Revista LiminaR. Estudios sociales y humanísticos, año 6, vol. VI, núm. 2, diciembre de 2008, Tuxtla Gutiérrez, Chiapas. ISSN: 1665-8027 
este modo siempre van al lugar a agradecerle, encenderle unas velas, beber con él y bailarle, entre otras actividades, pero sólo entre ellos, aunque aceptan a quien se acerca a acompañarlos. Desde ese día una de las imágenes del Gauchito no está más en su urna ya que fue obsequiada a uno de nosotros para que nos acompañe, así como nos fue entregada una llave de la puerta de dicha urna para poder abrirla y encender una vela al pasar.

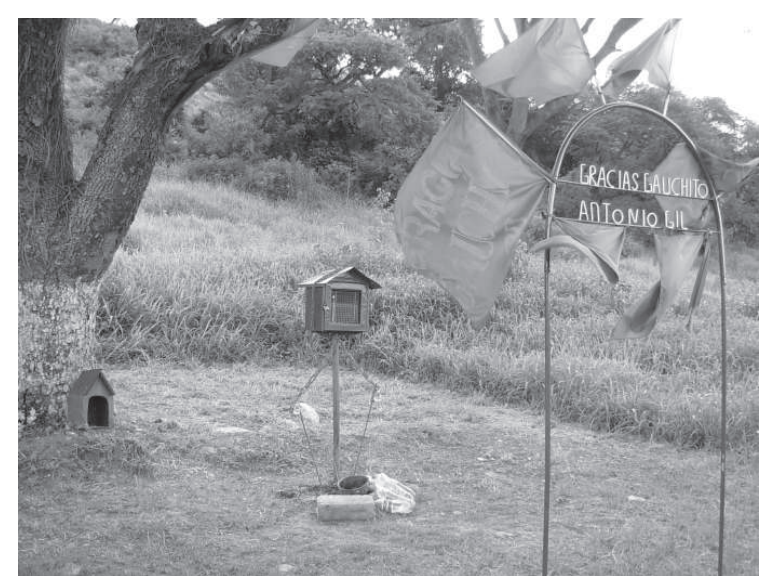

2006 - Jujuy. R. A. (Ruta Nac. 9, orientación norte sur, mano derecha. Alto Comedero). Gauchito Gil, según nuestra descripción Santuario Norte (foto: archivo personal).

En cuanto al que denominamos Santuario Sur, éste ofrecía el aspecto de una romería por el volumen de gente que estaba presente, inclusive había apoyatura de la policía para ordenar los vehículos. Como ya dijimos, quien controla el lugar es una señora que dice ser la dueña de la imagen y manifiesta que fue tallada por su hijo. En este caso la infraestructura es bastante importante, hay un tinglado, el piso es de cemento, además de las construcciones ya mencionadas.

En el lugar se había delimitado un espacio en el que fue colocada la imagen del Gauchito, el mismo estaba rodeado de velas rojas, hasta él se acercaban los devotos y la dueña, a modo de oficiante, con un clavel en la mano que embebía en 'agua bendita' asperjaba a los devotos que a ella se acercaban y luego les obsequiaba un recuerdo (vela roja) de la visita.

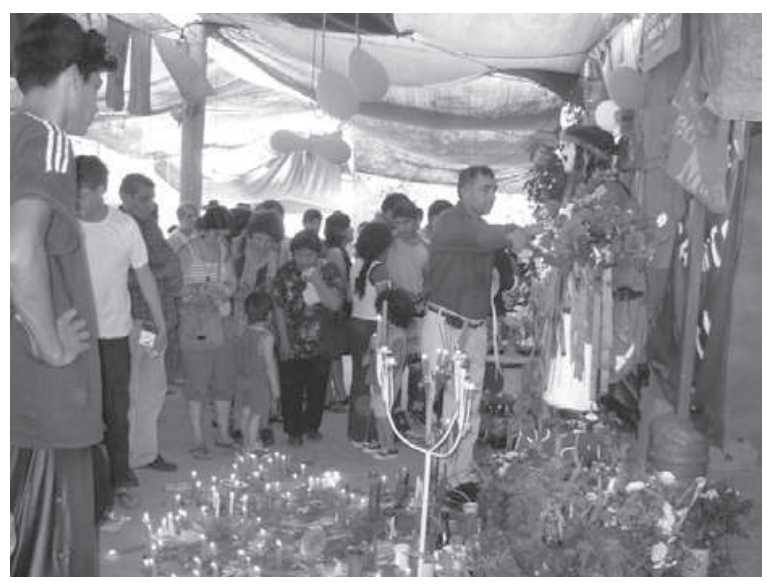

2006, Jujuy. R. A., (Ruta Nac. 9, orientación norte sur, mano derecha. Alto Comedero), Gauchito Gil, según nuestra descripción Santuario Sur (foto: archivo personal).

La señora de referencia manifiesta desconocer el origen de los santuarios a San La Muerte que flanquean a su Gauchito, así como a sus correspondientes dueños. No obstante ambas construcciones, con su proliferación de San La Muerte, estaban abiertas, con sus cuidadores respectivos, sus velas y devotos visitantes.

En este Santuario Sur, con fuerte coexistencia de estas dos devociones, también el clima era distendido con un equilibrio entre lo sagrado y lo profano, el primer aspecto resuelto en diversos aspectos rituales y, el segundo, en actividades varias como comer, cantar, charlar, pasear, adquirir productos ofrecidos por ocasionales vendedores entre otras actividades.

\section{Consideraciones finales}

El análisis de los materiales nos lleva a reflexionar acerca de cómo el paisaje ritual da cuenta de los espacios 
sagrados instaurados por la gente; en dicho paisaje, que es el ámbito del culto social, se puede distinguir tanto las ermitas y cruces que recuerdan los lugares en los que ha acaecido una muerte trágica, como aquellos erigidos para veneración de las canonizaciones populares. Es evidente la vinculación entre esas devociones populares y el culto a los muertos, o culto a las ánimas, del cual se escinden a partir de alguna circunstancia particular, para adquirir una nueva dimensión y dinámica propia, similar a la de los santos validados por la Iglesia Católica.

Intentamos con este trabajo aportar al estudio de la religiosidad tradicional/popular, al analizar en parte uno de sus aspectos como es el del culto a los muertos $\mathrm{y}$ a las devociones populares vinculados al primero en el contexto de países de tradición católica, en los que el culto a los santos ha sido central en la pastoral a lo largo de los años y, por ende, la religiosidad del pueblo ha ido recreando un santoral que fluctúa entre lo oficial y lo no oficial. Por otra parte, como entendemos que en la ideología del catolicismo el culto a los santos (oficiales o no) tiene estrechos lazos con el culto a los muertos, consideramos que las ermitas y cruces de los caminos (erigidas como señal de muertes trágicas y lugar para encendido de velas entre otros pequeños actos rituales) son el punto de inflexión, de articulación y liminal entre el culto privado a los muertos familiares y el culto a los santos populares en el denominado culto social.

Finalmente hemos considerado importante puntualizar (y distinguir) los espacios de culto de algunas canonizaciones populares que se encuentran en los cementerios ya que estos últimos son lugares normados institucionalmente $y$, sin embargo, es evidente que a pesar de estar en conocimiento de que se presentaron algunos conflictos, finalmente dichos espacios han quedado validados por el accionar de hecho de los propios devotos que son, en última instancia, los portadores y recreadores de la religiosidad tradicional/popular.

\section{Notas}

${ }^{1}$ Como por ejemplo la creencia y el culto a la Pachamama (la Madre Tierra) con plena vigencia.

${ }^{2}$ Por ejemplo la organización de concursos de "adoraciones" de Navidad, así como los de pesebres y la invitación a participar en las procesiones organizadas por las Parroquias a los promesantes (que hacen "adoraciones") en los oratorios particulares para imágenes del catolicismo de propiedad privada. En todos los casos consideramos que se trata de estrategias tendientes a vaciar de sentido las expresiones de la religiosidad tradicional/popular, cuestión que he planteado en trabajos anteriores.

${ }^{3}$ Como sucede con diferentes aspectos que confluyen en la organización y prácticas de los oratorios privados (tema ampliamente tratado por la autora en publicaciones previas) y en las de las devociones populares.

${ }^{4} \mathrm{Al}$ respecto no dejamos de tener en cuenta las estrategias misionales de las órdenes religiosas de misioneros, como la de los Padres Claretianos, que consideran algunos aspectos de la religiosidad tradicional/popular en particular las devociones a imágenes de propiedad privada y el respeto por la creencia en la Pachamama, tema que no abordamos en este trabajo.

${ }^{5}$ Apacheta: Montículo de piedras en honor a la $\mathrm{Pa}$ chamama (Madre Tierra) ubicado en lugares estratégicos tales como cruces de caminos entre otros, en los que realizan diversos rituales a dicha deidad.

${ }^{6}$ En este caso nos referimos a construcciones destinadas a honrar a las devociones populares o canonizaciones populares.

${ }^{7}$ Por ejemplo, en algunos casos, los espacios de la tierra que se abren para realizar los rituales de "desentierro del Carnaval"; también algunos que se encuentran en los terrenos y que están reservados para los ritos a la 
Pachamama del mes de agosto y que, a simple vista, no se advierten; sin embargo siempre están allí.

${ }^{8}$ Caso similar es el de la Difunta Correa, canonización popular profundamente estudiada por Sara Newbery y Susana Chertudi que en la actualidad, y frente a la expansión del Gauchito Gil, parece haber ingresado en un período de detenimiento.

${ }^{9}$ San La Muerte: devoción popular a un santo sin existencia real, de gran difusión en la región chaqueña de la República Argentina, se trata de la figura de un esqueleto, de pie o sentada (puede o no tener guadaña) a la que se encomienda la gente con diversos fines, entre otros preservarse de la muerte y tener una buena muerte.

${ }^{10}$ Al emplear la expresión "dueños del lugar" nos referimos a la/s personas que han instaurado la imagen del Gauchito en el lugar y se encargan de cuidarlo y de realizar las actividades que consideran pertinentes, de modo que son dueños del santuario pero no del terreno que es fiscal, situación que no excluye la existencia de espacios de propiedad privada que pudiera haber en otros lugares.

${ }^{11}$ Ídem nota 2.

\section{Bibliografía}

Bosca, Roberto, 1998, "Gilda: El Ángel de la bailanta. Reflexiones sobre los cultos populares y del star system en la Argentina", en Scripta Ethnologica, vol. XX. CAEACONICET. Bs. As.

Cioce, Damián Pedro, 2004, "Ermitas y cruces de los caminos en la zona sur del gran Bs. As. Fines del Siglo XX. Pervivencia de una manifestación cultural ante la muerte trágica", en Folklore Latinoamericano, tomo V, 2001, edic. Confolk, Buenos Aires.

—, 2005, “Caminos de las ermitas'. Recreación de expresiones de religiosidad popular", en Folklore Latinoamericano, tomo VII - 2003-2004, edic. Confolk, Buenos Aires.

Colatarci, María Azucena, 1994, "Aportes para el estudio de las celebraciones vigentes en la puna jujeña (R. A.)", en Mitológicas, vol. 9, CAEA/CONICET. Bs. As. —, 1994, "Modificaciones en las celebraciones de la puna jujeña como resultado de la mediación institucional", en Scripta Ethnologica, vol. XVI, CAEA. Buenos Aires.

—, 1995, "Persistencia y emergencia del culto a la Tierra en la puna jujeña”, en I Congreso Argentino de Americanistas, 1992, tomo II, Facultad de Filosofía y Letras, UBA. Buenos Aires.

—, 2005, "Celebración en Iruya (NOA)", en Folklore Latinoamericano, tomo VII, 2003-2004, edic. Confolk, Buenos Aires.

Colatarci, María Azucena y Ricardo Vidal, 2007, “¿Culto a los muertos o devoción popular? Algunas reflexiones...", en Anthropos 2007, Cuba.

Coluccio, Félix, 1986, Cultos y canonizaciones populares de Argentina, ediciones del Sol. 6. Bs. As.

—, 1995, Las devociones populares argentinas, Nuevo Siglo, Bs. As.

Chertudi, Susana y Sara Josefina Newbery, 1978, La Difunta Correa, editorial Huemul. Buenos Aires.

Chumbita, Hugo, 1999, "Sobre los estudios del bandolerismo social y sus proyecciones”, en Revista de Investigaciones Folclóricas, núm. 14, Bs. As.

Fernández Latour de Botas, Olga, 1998, Mitos y creencias, La Nación, Bs. As.

Geertz, Clifford, 1987, La interpretación de las culturas, Gedisa, México.

Gutiérrez de Prado, Silvia, 2000, "Veneración a las almas milagrosas (una práctica viva)", en Cultos. Relatos y Ceremonias en la Religiosidad Popular. Grupo de Estudio Mythos y Logos, coordinadora María Eugenia Valentié, Facultad de Filosofía y Letras, Universidad Nacional de Tucumán, Tucumán.

Krause Yornet, Ma. Cristina, 1994, "Las Ánimas: Un subsistema autónomo de la religión popular", en Mitológicas, vol. 9, CAEA-CONICET, Bs. As.

Krause Yornet, Ma. Cristina y Jorge Edmundo Delgado, 1998, "Un culto puertas adentro. Reflexiones sobre 
la religiosidad sanjuanina", en Scripta Ethnologica, vol. XX, CAEA-CONICET, Bs. As.

Plath, Oreste, 1995, L'Animita. Hagiografía Folclórica, editorial Grijalbo, Chile.

Rosenberger, Tobías, 1994, Upamarca. El país del silencio. El Folklore de la Muerte en el Tucumán, Universidad Nacional de Tucumán.
Wainziger, Elsa, 2000, "Rituales de la muerte en el NOA: 'La alumbrada'. Celebración religiosa popular. Meditación en torno a la presencia y ausencia de los rituales de la muerte", en Cultos. Relatosy Ceremonias en la Religiosidad Popular. Grupo de Estudio Mythos y Logos, coordinadora María Eugenia Valentié, Facultad de Filosofía y Letras, Universidad Nacional de Tucumán, Tucumán. 